\title{
RESEARCH
}

Open Access

\section{Dietary fat quantity and quality in relation to general and abdominal obesity in women: a cross-sectional study from Ghana}

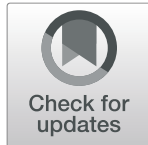

\author{
Sufyan Bakuri Suara', Fereydoun Siassi ${ }^{1 *}$, Mahama Saaka ${ }^{3}$, Abbas Rahimi Foroshani ${ }^{4^{*}}$, Sara Asadi ${ }^{2}$ and \\ Gity Sotoudeh ${ }^{2 *}$
}

\begin{abstract}
Background: Although relationships between obesity and total fat and fat types have been widely examined, the associations between the relative proportions of fatty acids calculated in the form of indices and obesity/overweight are lacking. The objective of this study was to assess associations between dietary fat quality indices and odds of obesity/overweight in women from Ghana.
\end{abstract}

Methods: In this cross-sectional study, dietary information was obtained using 24-h dietary recall. The odds of obesity were evaluated across quintiles of specific DFQ indices [atherogenicity index (Al), thrombogenic index (TI), hypo- and hypercholesterolemic fatty acids ratio $(\mathrm{h} / \mathrm{H})$, omega-3 to omega- 6 polyunsaturated fatty acids ratio $(\Sigma \omega-3 / \Sigma \omega-6)$, polyunsaturated fatty acids/saturated fatty acids ratio (PSR), dietary lipophilic index (LI) and percentage of energy from total fat (TF)].

Results: After adjustment for covariates, general obesity and overweight were inversely associated with $\sum \omega-3 /$ $\sum \omega-6$ ratio (OR: $0.63 ; 95 \% \mathrm{Cl}: 0.24-1.63 ; \mathrm{P}$ for trend $\left.(\mathrm{P})=0.005\right)$ and positively with $\mathrm{TI}(4.14 ; 95 \% \mathrm{Cl}: 1.78-9.66$; $P=0.01)$ and $\mathrm{LI}(2.49 ; 95 \% \mathrm{Cl}: 1.14-5.43 ; \mathrm{P}=0.01)$. The odds of abdominal obesity based on waist circumference (WC) were significantly higher among participants in the fifth quintile $(\mathrm{Q})$ compared with those in the first $\mathrm{Q}$ of $\mathrm{Al}(1.24 ; 95 \% \mathrm{Cl}$ : $0.56-2.74 ; \mathrm{P}=0.01)$, TI (4.14; $95 \% \mathrm{Cl}: 1.78-9.66 ; P=0.009)$, LI $(2.11 ; 95 \% \mathrm{Cl}: 0.98-4.55 ; P=0.02)$ and TF $(1.59 ; 95 \% \mathrm{Cl}:(0.73-$ $3.46 ; P=0.003)$. Similarly, waist to height ratio $(\mathrm{WHtR})$ was positively associated with $\mathrm{Al}(2.89 ; 95 \% \mathrm{Cl}: 1.32-6.31 ; P=0.04)$, Tl (2.65; 95\% Cl: 1.22-5.76; $P=0.03)$, LI (3.32; 95\% Cl: $1.52-7.28 ; P=0.007)$ and TF $(1.83 ; 95 \% \mathrm{Cl}: 0.85-3.93 ; P=0.009)$.

Conclusion: There was an inverse association between $\Sigma \omega-3 / \Sigma \omega-6$ ratio and general obesity and WC. We also found positive associations between abdominal obesity and Al and TF. Furthermore, TI and LI showed positive relationships with both general and abdominal obesity. Therefore, intake of dietary fatty acids in favor of higher ratios of $\Sigma \omega-3 / \Sigma \omega-6$ may be important in obesity prevention.

Keywords: Atherogenicity index, Thrombogenic index, Lipophilic index, Obesity, Overweight

\footnotetext{
* Correspondence: siassif@tums.ac.ir; rahimifo@tums.ac.ir;

gsotodeh@tums.ac.ir

${ }^{2}$ Department of Community Nutrition, School of Nutritional Sciences and

Dietetics, Tehran University of Medical Sciences, Hojatdost street, Naderi

street, Keshavarz Blv, Tehran, Iran

${ }^{4}$ Department of Statistics and Epidemiology, School of Public Health, Tehran

University of Medical Sciences, Tehran, Iran

Full list of author information is available at the end of the article
}

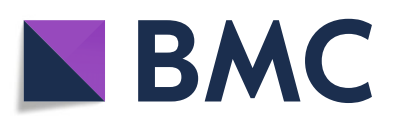

(- The Author(s). 2020 Open Access This article is licensed under a Creative Commons Attribution 4.0 International License, which permits use, sharing, adaptation, distribution and reproduction in any medium or format, as long as you give appropriate credit to the original author(s) and the source, provide a link to the Creative Commons licence, and indicate if changes were made. The images or other third party material in this article are included in the article's Creative Commons licence, unless indicated otherwise in a credit line to the material. If material is not included in the article's Creative Commons licence and your intended use is not permitted by statutory regulation or exceeds the permitted use, you will need to obtain permission directly from the copyright holder. To view a copy of this licence, visit http://creativecommons.org/licenses/by/4.0/. The Creative Commons Public Domain Dedication waiver (http://creativecommons.org/publicdomain/zero/1.0/) applies to the data made available in this article, unless otherwise stated in a credit line to the data. 


\section{Introduction}

The prevalence of obesity and overweight are increasing globally and if the current trends are not controlled, 2.16 billion and 1.12 billion adults are likely to become overweight and obese, respectively, in the next decade [1, 2]. A previous review revealed alarming prevalence (43\%) of overweight and obesity in Ghanaian adults [3]. According to epidemiological studies, the disease burden of obesity is enormous, it increases the risk of infertility in women $[4,5]$, metabolic syndrome $[6,7]$, cardiovascular diseases, type 2 diabetes mellitus (T2DM), chronic kidney disease [8], multiple cancers [9] and musculoskeletal complications [10, 11].

Although genetic factors play a role in the development of obesity $[12,13]$, the contributions of both total dietary fat $[14,15]$ intake and fat types [12, 13] have been suggested. However, the relationship between dietary fats and obesity is debatable [12, 14-21]. Specifically, positive [14, 15] and inverse [16] associations have been reported between total fat intake and obesity.

Moreover, previous studies suggested both positive [12, 14] and inverse [17] associations between dietary saturated fatty acids (SFAs) intake and weight gain. Furthermore, both positive [13, 14] and negative [18] relationships between monounsaturated fatty acids (MUFAs) intake and the chance of obesity have been found. Additionally, inverse $[19,20]$, null $[14,21]$ and positive [14] associations have been reported between polyunsaturated fatty acid (PUFA) consumption and the chance of obesity.

Typically, the fats and oils dietary pattern amongst Ghanaians is characterized by palm oil, shea butter and margarine $[22,23]$. These fats have a high SFA content [24]. Palm oil, for example, contains approximately 50\% SFA [24, 25] and Ghanaian shea butter has $45.9 \%$ stearic acid [26]. In two cross-sectional studies, this dietary pattern showed null [23] and unexpectedly inverse associations with general and abdominal obesity in Ghanaian adults [27].

Evidence from the above discrepant results may suggest that total fat intake and the absolute quantities of individual fatty acids consumed are not sensitive enough to reveal a consistent relationship between dietary fat and obesity. Therefore, the relative proportions of fatty acids instead of their absolute quantities in the diet may be an enhanced approach to investigate the relationship between dietary fat consumption and prevalence of obesity. In a previous study in French adults, low dietary PUFAs to SFAs ratio was found to accentuate the risk of being generally and abdominally obese [12]. In Africa, a prospective study found higher intake of unsaturated fatty acids to SFAs ratio and $\sum \omega-6 / \sum \omega-3$ ratio in normal weight compared with overweight/obese individuals with and without T2DM [18]. A major limitation in the African study was that the effect of dietary energy was not accounted for in the analysis [18], which could seriously confound the results [28, 29]. However, in Danish cohort, Lund et al. [19] did not find a significant association between $\sum \omega-3 / \sum \omega-6$ ratio with waist circumference and body mass index.

In addition to traditional approaches such as polyunsaturated fatty acids/saturated fatty acids ratio (PSR), and $\sum \omega$ $3 / \sum \omega-6$ ratios as stated in the preceding paragraph, a number of promising fat quality indices have been published to aid the evaluation of dietary fat quality (DFQ) in relation to health outcomes. First, Ulbricht and Southgate [30], in the early 90s, proposed the atherogenicity index (AI) and thrombogenicity index (TI), which consider the ratio of subclasses of SFAs to MUFAs and PUFAs. Subsequently, Santos-Silva et al. [31] published a fat quality index which considers the ratio between low cholesterol and high cholesterol raising fatty acids ( $\mathrm{h} / \mathrm{H}$ ratio) in foods. Later, Ding et al. [32] introduced the lipophilic index (LI) which has the ability to estimate the fluidity of biological specimens including cholesterol particles in the presence of fatty acids consumed or endogenously synthesized. Largely, previous work has focused on relationships between AI, TI, h/H or LI and incidence of gestational diabetes [33] and risk of myocardial infarction [34]. By considering the predictive effect of excess body weight gain on insulin sensitivity [35] and the importance of obesity in the development of many other chronic diseases including metabolic syndrome [6], it is imperative that scientists examine the association between the above fat quality indices and the odds of obesity. This may be a novel strategy for the development of nutrition policies that are beneficial for the prevention of obesity and excessive weight gain. It has not yet been established whether AI, TI, h/H ratio, $\Sigma \omega-3 / \sum \omega-6$ ratio, PSR or LI is associated with obesity/overweight in Ghana, a country faced with high prevalence of obesity and overweight [3]. Therefore, the purpose of this study was to investigate the relationship between general and abdominal obesity and six complementary fat quality indices (AI, TI, h/H ratio, $\Sigma \omega-3 /$ $\sum \omega-6$ ratio, PSR, LI) and percentage of energy from total fat in women.

\section{Methods and materials \\ Study design and population}

This cross-sectional study was carried out among a randomly selected 295 women (aged 18-59 years) who live within Tamale Metropolis, Tamale, Ghana. Participation in this study was voluntary and participants also consented to the study without being coaxed. We collected data in August and September 2018. Based on our predefined criteria, potential participants of a reported history of myocardial infarction, renal disease or suffering from other major illnesses (diabetes, human immune deficiency virus, renal disease, cardiovascular diseases and malaria) were not allowed to take part in the study. Furthermore, the study excluded women with self-reported severe nausea and vomiting as well as those who were pregnant or lactating prior to recruitment. Moreover, we 
excluded women who were put on specific diet therapies or had been restricted from consuming a variety of foods. The study sample size was computed based on a hypothesized correlation coefficient of 0.2 between indices of fat quality and BMI, waist circumference (WC) and waist to height ratio (WHtR). Our pre-defined confidence level for the study was 95 and $80 \%$ power of test. Based on an established protocol for estimating sample sizes in cross-sectional studies by Rosner [36], a total of 195 women were first computed. In order to increase the power of the statistical results and to cater for nonresponse rate the 195 was multiplied by 1.5 , which finally raised the final sample size to 295 subjects.

\section{Anthropometric assessment}

Body weight was measured to the nearest $100 \mathrm{~g}$ using a Seca weighing scale (Seca weighing scale: Seca gmbh and co.kg; 22,089 Hamburg, Germany; Model: 8741321009; designed in Germany-made in China). Height measurement was by the use of United Nations Children Emergency Fund height board. The values were recorded to the nearest $0.1 \mathrm{~cm}$. We calculated BMI as weight (in kilograms) divided by the height (in meters squared). BMI $\leq 24.9 \mathrm{~kg} / \mathrm{m}^{2}$ was considered absence of general overweight and obesity. BMI values of $25-29.9 \mathrm{~kg} / \mathrm{m}^{2}$ and $\mathrm{BMI} \geq 30 \mathrm{~kg} / \mathrm{m}^{2}$, defined overweight and general obesity, respectively [37]. The WC was measured based on World Health Organization guidelines thus, at the mid-point between the lower border of the rib cage and the iliac crest using a non-stretchable fiber-glass measuring tape. All WC values were recorded to the nearest $0.1 \mathrm{~cm}$. Participants were dichotomized based on WC value [(normal: $\mathrm{WC}<80 \mathrm{~cm}$ and abdominal obesity: $\mathrm{WC} \geq$ $80(\mathrm{~cm})$ ] [38]. We calculated WHtR by dividing WC $(\mathrm{cm})$ by the measured height $(\mathrm{cm})$. WHtR $\geq 0.5$ was adopted for the presence of overweight and abdominal obesity for the purpose of uniformity regarding age differences whereas, WHtR $\leq 0.5$ considered absence of overweight and abdominal obesity [39].

\section{Assessment of demographic and lifestyle factors}

Information about demographic and lifestyle factors such as age, educational status, marital status, occupation, household size, household assets, parity, and physical activity were obtained using a structured questionnaire following face-to-face interviews. In order to estimate their economic status, we enumerated household assets for households that the selected study participants belong. Based on the list of items reported and the make-up of their rooms, we calculated a summary value as a proxy for economic status. Physical activity level of participants was measured using the International Physical Activity Questionnaire short form [40]. The reliability and validity of these questionnaires were assessed across 12 countries and the results showed they can be applied in many settings and in different languages [41]. With these questionnaires, we asked questions about the time and the number of days within the previous seven (7) days a person spent on walking, doing moderate-intensity activity and/or doing vigorous-intensity activities. The overall physical activity level in metabolic equivalent minutes per week (MET-minutes/week) was calculated by summing the totals for walking activity, moderate activity and vigorous activity in MET-minutes/week scores.

\section{Dietary intake}

All dietary data were obtained based on repeated nonconsecutive 2-day 24-h dietary recalls. We used real food items, food models and standard kitchen weighing equipment to guide food portion size estimation. We deployed a trained caterer for the interviews. Absolute quantities of dietary fatty acids were determined using standard portion sizes of food items from the United States Department of Agriculture Food Composition Databases [42] due to a lack of local database on this issue. For the same reason, we obtained melting points of dietary fatty acids from the Japanese Lipid Bank database [43]. The mean values of daily intake of total fat, fatty acids, and energy for the two days were used in the analysis.

We calculated energy percentage from fat (TF) from dividing average dietary energy obtained from fat (kcals) by average daily total energy intake, and finally expressed the results as $100 \%$. Also, we calculated DFQ indices from established protocols as detailed below.

Polyunsaturated fatty acids/saturated fatty acids ratio $($ PSR $)=$ PUFAs: SFAs ratio (1) [30].

Atherogenicity index $(\mathrm{AI})=\left(12: 0+\left(\begin{array}{l}4 \\ \mathrm{x}\end{array} \mathrm{14:0}\right)+16: 0\right) /$ $\left(\sum \omega-6\right.$ PUFA $+\sum \omega-3$ PUFA + $\sum$ MUFA $\left.\omega-9\right)$ (2) [30]; where 12:0 = lauric acid,14:0 = myristic acid, 16:0 = pal mitic acid, $\Sigma \omega-6$ PUFA = sum of omega- 6 polyunsaturated fatty acids, $\Sigma \omega-3$ PUFA = sum of omega- 3 polyunsaturated fatty acids, and $\Sigma$ MUFA $\omega-9=$ sum of omega- 9 monounsaturated fatty acids.

Thrombogenic index $\quad(\mathrm{TI})=[(14: 0+16: 0+18: 0) \quad /$ $\left[\left(0.5 \sum\right.\right.$ MUFA $\left.)\right]+\left(0.5 \sum \omega-6\right.$ PUFA $)+\left(3 \sum \omega-3\right.$ PUFA $)+(\Sigma$ $\omega-3$ PUFA / $\sum \omega-6$ PUFA)] (3) [30]; where 14:0 = myristic acid, 16:0 = palmitic acid, 18:0 = stearic acid, MUFA = monounsaturated fatty acids, $\sum \omega-6$ PUFA $=$ sum of omega- 6 polyunsaturated fatty acids, $\Sigma \omega-3$ PUFA $=$ sum of omega-3 polyunsaturated fatty acids.

hypo- and hypercholesterolemic fatty acids ratio (h/ $\mathrm{H})=(18: 1 \omega-9+18: 2 \omega-6+20: 4 \omega-6+18: 3 \omega-3+20: 5$ $\omega-3+22: 5 \omega-3+22: 6 \omega-3 /(14: 0+16: 0)$ (4) [31]; where 18:1 $\omega-9=$ oleic acid, 18:2 $\omega-6=$ linoleic acid, 20:4 $\omega-6=$ arachidonic acid, 18:3 $\omega-3=$ alpha-linolenic acid, 20:5 $\omega$ $3=$ eicosapentaenoic acid, 22:5 $\omega-3=$ docosapentaenoic acid, 22:6 $\omega-3=$ docosahexaenoic acid, 14:0 = myristic acid, 16:0 = palmitic acid, $\mathrm{h} / \mathrm{H}=$ hypo- and hypercholesterolemic fatty acids ratio. 
$\sum \omega-3 / \sum \omega-6$ ratio (5) [30]; where $\sum \omega-3=$ sum of omega-3 polyunsaturated fatty acids, $\sum \omega-6=$ sum of omega- 6 polyunsaturated fatty acids.

The lipophilic index of dietary intake was computed by multiplying the intake of each fatty acid (in grams) by its specific melting point $\left({ }^{\circ} \mathrm{C}\right)$, adding the products, and then dividing by the total of fatty acid intake (in grams) [34].

Dietary lipophilic index $(\mathrm{LI})=\sum[$ Fatty acid $(\mathrm{g}) \mathrm{i} \times$ Melting point $\left.\left({ }^{\circ} \mathrm{C}\right) \mathrm{i}\right] /$ Fatty acid (g) i (6) [32]; where LI = dietary lipophilic index.

\section{Statistical analysis}

All data were checked for compliance with the selected statistical techniques. The Kolmogorov-Smirnov test was used to evaluate the normality of the data distribution. To use physical activity as a continuous variable in our regression models, it was first transformed (natural logarithm) because it was positively skewed. Based on our predefined dietary energy cut-off values, subjects were excluded whose reported average dietary energy intake levels were below $<500 \mathrm{kcal} / \mathrm{d}$ or above $>3500 \mathrm{kcal} /$ d [44]. Out of the 295 subjects sampled for the study, we excluded 18 participants because their reported dietary energy intakes were outside the cut off values.

The DFQ indices were energy-adjusted using the residual method [45]. Energy-adjusted AI, TI, h/H ratio, $\Sigma \omega-3 / \sum \omega-6$ ratio, PSR, LI, and TF were used to classify participants into quintiles (Qs). Participants were also dichotomized as those with and without overweight and obesity based on BMI, WC, and WHtR. The means \pm standard deviations (SDs) for socio-demographic factors were reported for continuous variables by the use of independent-sample t-test in participants classified as having obesity/overweight and those without obesity/overweight whereas frequencies and percentages were presented for categorical variables using a Chi-square test. Additionally, we compared means and standard deviations for BMI, WC, and WHtR across the Qs of DFQ indices, using a One-way analysis of variance (ANOVA). Binary logistic regression was used to determine the odds ratios (ORs) and 95\% confidence intervals (CIs) for the presence of general and abdominal obesity across Qs of DFQ indices in unadjusted and multivariableadjusted models. The possible effects of all potential confounding variables that showed a significant relationship with measures of obesity and overweight were adjusted. In this context, age (continuous); asset score (continuous); physical activity level (natural log-transformed); dietary energy/kcal (continuous); woman education (categorical); husband education (categorical); occupation woman (categorical); occupation husband (categorical); marital status (categorical) were entered into the adjusted regression models. The IBM Statistical Package for Social Sciences (version 24; SPSS Inc.) was used for all statistical analyses.
We considered $P<0.05$ to be statistically significant for all analyses.

\section{Results}

Of the 277 women assessed, 22.7\% were overweight according to BMI indicator, $9.4 \%$ had general obesity based on BMI, and 32.5 and $39.4 \%$ had abdominal obesity based on WC and high WHtR, respectively. Characteristics of study participants based on obesity/overweight status are presented in Table 1. Participants who had general obesity ( $\mathrm{P}$ for trend $=0.01$ ), abdominal obesity based on WC (P for trend $<0.001$ ), and high WHtR (P for trend $<0.001$ ) were older, when compared with those without obesity. Similarly, the highest average asset score was found in participants classified as having general obesity ( $\mathrm{P}$ for trend $=$ 0.003), abdominal obesity based on both WC ( $\mathrm{P}$ for trend $<0.001$ ) and high WHtR (P for trend $=0.03$ ) in comparison with their respective counterparts without obesity.

Anthropometric measures according to DFQ indices are presented in Table 2. According to the findings, mean BMI decreased significantly from the lowest to the highest $\mathrm{Q}$ of $\mathrm{h} / \mathrm{H}$ ratio $(\mathrm{p}$-trend $=0.04)$. However, this relationship attenuated after adjustment for age, asset score, physical activity level, total dietary energy, woman education, husband education, occupation woman, occupation husband and marital status (p-trend =0.6). In the context of TI Qs, the mean BMI (p-trend =0.04) and WC (p-trend =0.03) increased significantly from the lowest to the highest $\mathrm{Q}$. These patterns in means weakened after adjustment for the covariates for both BMI (p-trend $=0.06$ ) and WC (ptrend $=0.07$ ). Moreover, after these adjustments for covariates, mean WHtR also increased significantly from the lowest to the highest Q of TI (p-trend = 0.03). Additionally, we observed that mean BMI significantly increased ( $\mathrm{p}$ trend $=0.04$ ) from the lowest to the highest $\mathrm{Q}$ of LI. This trend was still significant even after adjustment for potential confounding factors ( $\mathrm{p}$-trend $=0.04$ ). Although an increase in mean WHtR across the lowest to the highest $Q$ of LI was found not to be significant ( $\mathrm{p}$-trend $=0.1$ ), in the unadjusted model, it was significant in the multivariableadjusted model ( $\mathrm{p}$-trend $=0.02$ ). Means of WC and WHtR did not show appreciable patterns with PSR, AI, $\sum \omega-3 / \sum \omega-$ 6 ratio and TF.

The ORs of obesity according to quintiles (Q) of fat types are presented in Table 3. Logistic regression analysis showed a positive association between total SFA and general obesity $\left(\mathrm{OR}_{\text {quintiles } 5}\right.$ vs.1 2.16 ; 95\% CI 0.99-4.70; ptrend $=0.02)$. However, after adjustment for age, asset score, physical activity level, total dietary energy, woman education, husband education, occupation woman, occupation husband, and marital status, the relationship was not remained significant $\left(\mathrm{OR}_{\text {quintiles }} 5\right.$ vs.1 $1.41 ; 95 \% \mathrm{CI}$ 0.53-3.78; p-trend $=0.2$ ). Additionally, SFA was positively associated with $\mathrm{WC}$ in both the unadjusted $\left(\mathrm{OR}_{\text {quintiles }} 5\right.$ 
Table 1 Characteristic of study participants according to subjects with obesity/overweight and without obesity/overweight

\begin{tabular}{|c|c|c|c|c|c|c|c|c|c|}
\hline \multirow[t]{2}{*}{ Variable } & \multicolumn{2}{|l|}{$\mathrm{BMI}\left(\mathrm{Kg} / \mathrm{m}^{2}\right)$} & \multirow[t]{2}{*}{$P$} & \multicolumn{2}{|l|}{ WC (cm) } & \multirow[t]{2}{*}{$P$} & \multicolumn{2}{|l|}{ WHtR } & \multirow[t]{2}{*}{$P$} \\
\hline & $\geq 25$ & $\leq 24.9$ & & $\geq 80$ & $<80$ & & $\geq 0.50$ & $<0.50$ & \\
\hline Age (years) & $38.1 \pm 10.7$ & $34.6 \pm 11.2$ & 0.01 & $39.5 \pm 10.2$ & $33.9 \pm 11.1$ & $<0.001$ & $39.3 \pm 10.7$ & $33.3 \pm 10.7$ & $<0.001$ \\
\hline Parity & $3.6 \pm 2.1$ & $2.9 \pm 1.9$ & 0.008 & $3.9 \pm 2.1$ & $2.8 \pm 1.9$ & $<0.001$ & $3.9 \pm 2.0$ & $2.6 \pm 1.9$ & $<0.001$ \\
\hline Household Size & $9.6 \pm 5.1$ & $10.8 \pm 6.3$ & 0.09 & $9.8 \pm 5.3$ & $10.8 \pm 6.3$ & 0.2 & $9.9 \pm 5.6$ & $10.8 \pm 6.1$ & 0.3 \\
\hline Asset score ${ }^{c}$ & $54.4 \pm 4.4$ & $52.8 \pm 3.9$ & 0.003 & $54.7 \pm 4.7$ & $52.6 \pm 3.7$ & $<0.001$ & $53.9 \pm 4.5$ & $52.8 \pm 3.8$ & 0.03 \\
\hline $\begin{array}{l}\text { Energy intake } \\
\text { (kcal/day) }\end{array}$ & $2154.9 \pm 663.7$ & $2048.1 \pm 694.7$ & 0.2 & $2303.3 \pm 677.5$ & $1976.1 \pm 665.4$ & $<0.001$ & $2223.9 \pm 672.8$ & $1990.5 \pm 679.8$ & 0.005 \\
\hline \multicolumn{10}{|l|}{ Physical Activity $^{\mathrm{a}}$} \\
\hline Low & $35(59.3)$ & $24(40.7)$ & & $38(64.4)$ & 21(35.6) & & 46(78.0) & 13(22.0) & \\
\hline Moderate & $42(26.9)$ & 114(73.1) & $<0.001$ & $42(26.9)$ & 114(73.1) & $<0.001$ & $52(33.3)$ & 104(66.7) & $<0.001$ \\
\hline High & 12(19.4) & $50(80.6)$ & & 10(16.1) & $52(83.9)$ & & $11(17.7)$ & $51(82.3)$ & \\
\hline \multicolumn{10}{|l|}{ Ethnicity } \\
\hline Dagomba & 68(30.9) & 152(69.1) & 0.2 & 68(30.9) & 152(69.1) & 0.1 & $84(38.2)$ & 136(61.8) & 0.4 \\
\hline Minority $^{b}$ & $21(36.8)$ & $36(63.2)$ & & $22(38.6)$ & $35(61.4)$ & & $25(43.9)$ & $32(56.1)$ & \\
\hline \multicolumn{10}{|l|}{ Marital Status } \\
\hline Married & 83(33.6) & 164(66.4) & 0.09 & $84(34.0)$ & 163(66.0) & 0.08 & $103(41.7)$ & $144(58.3)$ & 0.02 \\
\hline Single & $6(20.0)$ & $24(80.0)$ & & $6(20.0)$ & $24(80.0)$ & & $6(20.0)$ & $24(80.0)$ & \\
\hline \multicolumn{10}{|l|}{ Woman Education } \\
\hline No formal Education & $59(35.5)$ & $107(64.5)$ & & 64(38.6) & $102(61.4)$ & & $74(44.6)$ & $92(55.4)$ & \\
\hline Primary/Middle/JHS & 12(21.1) & 45(78.9) & 0.01 & 11(19.3) & $46(80.7)$ & 0.02 & 13(22.8) & $44(77.2)$ & 0.01 \\
\hline SHS/Tertiary & 18(33.3) & $36(66.7)$ & & 15(27.8) & $39(72.2)$ & & $22(40.7)$ & $32(59.3)$ & \\
\hline \multicolumn{10}{|l|}{ Husband Education } \\
\hline No formal Education & $46(35.4)$ & $84(64.6)$ & & $45(34.6)$ & $85(65.4)$ & & $58(44.6)$ & $72(55.4)$ & \\
\hline Primary/Middle/JHS & $6(10.0)$ & $54(90.0)$ & $<0.001$ & $8(13.3)$ & $52(86.7)$ & $<0.001$ & $8(13.3)$ & $52(86.7)$ & $<0.001$ \\
\hline SHS/Tertiary & $32(56.1)$ & 25(43.9) & & $32(56.1)$ & $25(43.9)$ & & $38(66.7)$ & 19(33.3) & \\
\hline \multicolumn{10}{|l|}{ Occupation of woman } \\
\hline Farmer & 16(38.1) & 26(61.9) & & 12(28.6) & 99(71.4) & & 15(35.7) & $27(64.3)$ & \\
\hline Trader & 48(31.6) & 104(68.4) & & 53(34.9) & $99(65.1)$ & & $68(44.7)$ & $84(55.3)$ & \\
\hline Salary/Service Sector & $9(29.0)$ & $22(71.0)$ & 0.8 & $6(19.4)$ & 25(80.6) & 0.3 & $8(25.8)$ & $23(74.2)$ & 0.1 \\
\hline Housewife & 16(30.8) & $36(69.2)$ & & 19(36.5) & $33(63.5)$ & & 18(34.6) & $34(65.4)$ & \\
\hline \multicolumn{10}{|l|}{ Occupation of husband } \\
\hline Farmer & 29(33.0) & $59(67.0)$ & & $26(29.5)$ & $62(70.5)$ & & $33(37.5)$ & $55(62.5)$ & \\
\hline Salary/Service Sector & $21(28.4)$ & 43(71.6) & 0.3 & $21(28.4)$ & $53(71.6)$ & 0.07 & $27(36.5)$ & $47(63.5)$ & 0.1 \\
\hline Trader & 33(38.8) & $52(61.2)$ & & $37(43.5)$ & $48(56.5)$ & & 43(50.6) & $42(49.4)$ & \\
\hline
\end{tabular}

Data are presented as mean \pm standard deviation and number (\%)

${ }^{a}$; Low ( $<600$ MET-minuts/week); Moderate ( $\geq 600$ but $<3000$ MET- minutes/week); High ( $\geq 3000$ MET-minutes/weeks), p-trend (p); Test of trend was conducted using ANOVA with contrast function for continuous variables and $\mathrm{X} 2$ test for categorical variables. $\mathrm{P}<0.05$ was considered as statistically significant ${ }^{\mathrm{b}}$ Gonja, gurusi, zambarama, Moshi, JHS (Junior High School); SHS (Senior High School, g/d: gram per day

${ }^{\mathrm{c}} \mathrm{An}$ ad hoc index of household asset score was computed from basically number of assets possessed from a list of items provided. A score of 1 point was given for an item owned. As for the main source of cooking energy, drinking water and toilet facility, 1 point was given for unimproved source and 2 points awarded for improved sources. The total score range was from 37 to 74 with higher scores suggesting enhanced economic strength. WC Waist circumference, BMI Body Mass Index, WHtR Waist to Height Ratio

vs.1 2.49 ; $95 \%$ CI 1.14-5.44; p-trend $=0.002)$ and the adjusted $\left(\mathrm{OR}_{\text {quintiles }} 5\right.$ vs.1 1.07 ; $95 \% \mathrm{CI} 0.37-3.12$; p-trend = $0.02)$ models. Also, SFA had a significant positive association with $\mathrm{WHtR}$ in the unadjusted model only $\left(\mathrm{OR}_{\text {quintiles }}\right.$ 5 vs.1 $2.64 ; 95 \%$ CI $1.22-5.71$; p-trend $=0.01$ ). In the unadjusted model, PUFA showed a positive association with
WC $\left(\mathrm{OR}_{\text {quintiles }} 5\right.$ vs.1 1.29 ; 95\% CI 1.19-6.10; p-trend = 0.01). However, in the adjusted model, this relationship was not significant. The $\sum \omega-3$ PUFAs and the $\sum \omega-6$ PUFAs did not show any relationship with obesity.

Logistic regression analysis showed an inverse association between $\Sigma \omega-3 / \sum \omega-6$ ratio and general obesity $\left(\mathrm{OR}_{\text {quintiles }} 5\right.$ 
Table 2 Anthropometric measures according to quintiles $(\mathrm{Q})$ of fat quality indices

\begin{tabular}{|c|c|c|c|c|c|c|c|c|c|}
\hline \multirow[t]{2}{*}{ Variable } & \multicolumn{3}{|l|}{$\mathrm{BMI}\left(\mathrm{Kg} / \mathrm{m}^{2}\right)$} & \multicolumn{3}{|l|}{$W C(\mathrm{~cm})$} & \multicolumn{3}{|l|}{ WHtR } \\
\hline & Mean \pm SD & P1 & $\mathrm{P} 2$ & Mean \pm SD & P1 & P2 & Mean \pm SD & P1 & P2 \\
\hline \multicolumn{10}{|l|}{ PSR } \\
\hline Q1 (55) & $25.2 \pm 5.2$ & & & $81.6 \pm 10.2$ & & & $0.50 \pm 0.06$ & & \\
\hline Q2 (56) & $22.0 \pm 5.2$ & & & $72.7 \pm 13.5$ & & & $0.46 \pm 0.08$ & & \\
\hline Q3 (55) & $22.5 \pm 3.6$ & 0.6 & 0.1 & $75.7 \pm 7.4$ & 0.9 & 0.06 & $0.47 \pm 0.05$ & 0.9 & 0.1 \\
\hline Q4 (56) & $24.5 \pm 4.1$ & & & $80.0 \pm 9.2$ & & & $0.50 \pm 0.06$ & & \\
\hline Q5 (55) & $23.5 \pm 4.2$ & & & $77.9 \pm 9.2$ & & & $0.48 \pm 0.06$ & & \\
\hline \multicolumn{10}{|l|}{$\sum \omega-3 / \Sigma \omega-6$} \\
\hline Q1 (55) & $21.6 \pm 4.4$ & & & $72.8 \pm 9.9$ & & & $0.46 \pm 0.06$ & & \\
\hline Q2 (56) & $23.9 \pm 4.6$ & & & $79.3 \pm 10.4$ & & & $0.50 \pm 0.07$ & & \\
\hline Q3 (55) & $24.3 \pm 4.9$ & 0.09 & 0.057 & $78.4 \pm 10.0$ & 0.1 & 0.03 & $0.48 \pm 0.06$ & 0.07 & 0.058 \\
\hline Q4 (56) & $25.4 \pm 4.2$ & & & $83.1 \pm 8.8$ & & & $0.52 \pm 0.06$ & & \\
\hline Q5 (55) & $22.5 \pm 4.4$ & & & $74.3 \pm 10.3$ & & & $0.47 \pm 0.07$ & & \\
\hline \multicolumn{10}{|l|}{$h / H$} \\
\hline Q1 (55) & $25.5 \pm 5.5$ & & & $81.4 \pm 12.4$ & & & $0.51 \pm 0.07$ & & \\
\hline $2(56)$ & $21.9 \pm 4.1$ & & & $73.0 \pm 8.9$ & & & $0.46 \pm 0.06$ & & \\
\hline Q3 (55) & $24.1 \pm 4.6$ & 0.04 & 0.6 & $78.9 \pm 11.3$ & 0.4 & 0.7 & $0.49 \pm 0.07$ & 0.2 & 0.7 \\
\hline Q4 (56) & $23.4 \pm 4.2$ & & & $77.3 \pm 8.6$ & & & $0.49 \pm 0.06$ & & \\
\hline Q5 (55) & $22.8 \pm 3 / 9$ & & & $77.4 \pm 9.5$ & & & $0.48 \pm 0.06$ & & \\
\hline \multicolumn{10}{|l|}{ Al } \\
\hline Q1 (55) & $22.8 \pm 4.1$ & & & $76.8 \pm 9.9$ & & & $0.47 \pm 0.06$ & & \\
\hline Q2 (56) & $24.2 \pm 4.4$ & & & $79.2 \pm 8.4$ & & & $0.49 \pm 0.06$ & & \\
\hline Q3 (55) & $23.5 \pm 3.6$ & 0.2 & 0.4 & $78.1 \pm 7.9$ & 0.5 & 0.3 & $0.48 \pm 0.05$ & 0.4 & 0.2 \\
\hline Q4 (56) & $21.7 \pm 4.9$ & & & $71.6 \pm 12.4$ & & & $0.45 \pm 0.08$ & & \\
\hline Q5 (55) & $25.4 \pm 5.3$ & & & $82.2 \pm 10.7$ & & & $0.51 \pm 0.07$ & & \\
\hline \multicolumn{10}{|l|}{ TI } \\
\hline Q1 (55) & $22.4 \pm 3.1$ & & & $74.7 \pm 7.1$ & & & $0.47 \pm 0.05$ & & \\
\hline Q2 (56) & $24.5 \pm 4.8$ & & & $80.5 \pm 10.7$ & & & $0.49 \pm 0.06$ & & \\
\hline Q3 (55) & $22.9 \pm 3.9$ & 0.04 & 0.06 & $75.8 \pm 9.0$ & 0.03 & 0.07 & $0.48 \pm 0.06$ & 0.06 & 0.03 \\
\hline Q4 (56) & $22.3 \pm 4.9$ & & & $75.1 \pm 12.4$ & & & $0.47 \pm 0.07$ & & \\
\hline Q5 (55) & $25.5 \pm 5.3$ & & & $82.0 \pm 10.8$ & & & $0.51 \pm 0.08$ & & \\
\hline \multicolumn{10}{|l|}{ LI } \\
\hline Q1 (55) & $22.9 \pm 3.8$ & & & $77.6 \pm 9.3$ & & & $0.48 \pm 0.05$ & & \\
\hline Q2 (56) & $23.9 \pm 4.3$ & & & $77.4 \pm 9.2$ & & & $0.48 \pm 0.06$ & & \\
\hline Q3 (55) & $23.2 \pm 4.5$ & 0.03 & 0.04 & $77.1 \pm 9.3$ & 0.2 & 0.07 & $0.48 \pm 0.06$ & 0.1 & 0.02 \\
\hline Q4 (56) & $21.9 \pm 4.7$ & & & $73.1 \pm 12.4$ & & & $0.46 \pm 0.07$ & & \\
\hline Q5 (55) & $26.0 \pm 5.1$ & & & $82.7 \pm 10.1$ & & & $0.52 \pm 0.06$ & & \\
\hline \multicolumn{10}{|l|}{ TF } \\
\hline Q1 (55) & $24.0 \pm 5.4$ & & & $79.8 \pm 12.7$ & & & $0.49 \pm 0.08$ & & \\
\hline
\end{tabular}


Table 2 Anthropometric measures according to quintiles $(\mathrm{Q})$ of fat quality indices (Continued)

\begin{tabular}{|c|c|c|c|c|c|c|c|c|c|}
\hline \multirow[t]{2}{*}{ Variable } & \multicolumn{3}{|l|}{$\mathrm{BMI}\left(\mathrm{Kg} / \mathrm{m}^{2}\right)$} & \multicolumn{3}{|l|}{$W C(\mathrm{~cm})$} & \multicolumn{3}{|l|}{ WHtR } \\
\hline & Mean \pm SD & P1 & P2 & Mean \pm SD & P1 & P2 & Mean \pm SD & P1 & P2 \\
\hline Q2 (56) & $23.7 \pm 4.2$ & & & $79.0 \pm 9.1$ & & & $0.49 \pm 0.05$ & & \\
\hline Q3 (55) & $23.3 \pm 3.8$ & 0.7 & 0.1 & $77.2 \pm 8.2$ & 0.06 & 0.03 & $0.48 \pm 0.05$ & 0.1 & 0.06 \\
\hline Q4 (56) & $22.2 \pm 3.9$ & & & $73.5 \pm 9.6$ & & & $0.46 \pm 0.06$ & & \\
\hline Q5 (55) & $24.4 \pm 5.3$ & & & $78.4 \pm 11.5$ & & & $0.48 \pm 0.07$ & & \\
\hline
\end{tabular}

$\mathrm{P}$ for trend (P1; unadjusted model test of trend using ANOVA with contrast function, P2; Significance level of test for trend association in adjusted linear regression model with adjustment for age (continuous); asset score (continuous); physical activity level (natural log transformed); dietary energy/kcal (continuous); woman education (categorical); husband education (categorical); occupation woman (categorical); occupation husband (categorical); marital status (categorical). In all multiple regression models, dummy variables were created for categorical covariates. To analyze the linear trends in the adjusted models, the median values of PSR, $\Sigma \omega-3 / \Sigma \omega-6, h / H, A l, T l, L I$ and TF were imputed for each quintile and the new variables were treated as continuous variables in linear regression model. TF; percentage of energy obtained from dietary fat. $P<0.05$ was considered statistically significant. WC Waist circumference, BMI Body Mass Index, WHtR Waist to Height Ratio, ANOVA One-Way Analysis of Variance, PSR polyunsaturated to saturated fatty acids ratio, $\Sigma \omega-3 / \Sigma \omega-6$; omega-3 to omega- 6 fatty acids ratio, $h / H$ hypo and hypercholesterolemic fatty acids ratio, Al Atherogenicity index, TI Thrombogenic index, LI Dietary lipophilic index, TF Percentage of energy from total fat

vs.1 0.63 ; 95\% CI 0.24-1.63; p-trend $=0.01)$. This relationship attenuated $\left(\mathrm{OR}_{\text {quintiles }} 5\right.$ vs.1 0.78 ; $95 \%$ CI $0.22-2.81$; ptrend $=0.005$ ) upon adjustment for the effects of age, asset score, physical activity level, total dietary energy, woman education, husband education, occupation woman, occupation husband, and marital status. Although in the unadjusted model, the analysis suggested a null association between $\Sigma \omega-3 / \Sigma \omega-6$ ratio and abdominal obesity defined by WC, in the adjusted model, there was a significant inverse association when the highest $\mathrm{Q}$ was compared with the lowest $\mathrm{Q}\left(\mathrm{OR}_{\text {quintiles }} 5\right.$ vs.1 0.73 ; $95 \% \mathrm{CI} 0.18-3.02$; p-trend = $0.02)$. Also, a significant inverse association was seen between $\mathrm{h} / \mathrm{H}$ ratio and high $\mathrm{WH} \mathrm{HR}$ when the highest $\mathrm{Q}$ of $\mathrm{h} /$ $\mathrm{H}$ ratio was compared with the lowest $\mathrm{Q}\left(\mathrm{OR}_{\text {quintiles }} 5\right.$ vs.1 0.29; 95\% CI 0.13-0.65; p-trend $=0.03$ ). Even after adjustment for covariates, this relationship remained significant. No relationship was found between the $\mathrm{h} / \mathrm{H}$ ratio and both general obesity and high WC. Moreover, PSR was not associated with obesity parameters.

In regard of the AI, a significant increase in the chance of general obesity $\left(\mathrm{OR}_{\text {quintiles }} 5\right.$ vs.1 $1.98,95 \%$ CI $0.91-$ 4.29; p-trend $=0.03$ ) among participants in the highest $\mathrm{Q}$ of AI emerged when compared with the lowest Q, however, this attenuated after adjustment for multiple confounders. Similarly, a significant increase in OR for abdominal obesity based on WC (OR quintiles 5 vs.1 1.24 , 95\% CI 0.56-2.74; p-trend $=0.008)$ and WHtR $\left(\mathrm{OR}_{\text {quin- }}\right.$ tiles 5 vs. $12.89,95 \%$ CI $1.32-6.31$; p-trend $=0.01$ ) was found among participants included in the highest Q of $\mathrm{AI}$ and remained significant even after adjustment for multiple confounders. When analysis was carried out, in the highest quintile of TI compared with the lowest quintile, the $\mathrm{OR}$ increased for general obesity $\left(\mathrm{OR}_{\text {quintiles }}\right.$ 5 vs.1 4.14, 95\% CI 1.78-9.66; p-trend $=0.003)$, abdominal obesity based on both WC ( $\mathrm{OR}_{\text {quintiles }} 5$ vs.1 $4.14,95 \% \mathrm{CI}$ 1.78-9.66; p-trend $=0.004)$ and high WHtR $\left(\mathrm{OR}_{\text {quintiles } 5}\right.$ vs.1 2.65, 95\% CI 1.22-5.76; p-trend $=0.02$ ) criteria. These observations remained unchanged upon multiple variable adjustments. Additionally, significant positive associations were observed between LI and general obesity $\left(\mathrm{OR}_{\text {quintiles }} 5\right.$ vs. $12.49,95 \% \mathrm{CI} 1.14-5.43$; p-trend = $0.006)$ and abdominal obesity as defined by both WC $\left(\mathrm{OR}_{\text {quintiles }} 5\right.$ vs.1 $2.11,95 \% \mathrm{CI} 0.98-4.55$; p-trend $\left.=0.01\right)$ and high WHtR ( $\mathrm{OR}_{\text {quintiles }} 5$ vs.1 $3.32,95 \% \mathrm{CI} 1.52-7.28$; p-trend $=0.004)$ and were still significant even after adjustment for covariates. In the unadjusted model, we found non-significant positive relationship between TF and abdominal obesity based on both WC and WHtR definitions, however, after multiple variable adjustment, we found significant positive associations between TF and abdominal obesity defined by both $\mathrm{WC}\left(\mathrm{OR}_{\text {quintiles }}\right.$ 5 vs. 1 1.59; 95\% CI, 0.73-3.46; P-trend $=0.003$ ) and high WHtR (OR quintiles 5 vs.1 1.83 ; $95 \%$ CI $0.85-3.93$; ptrend $=0.009)($ Table 4$)$.

\section{Discussion}

The present study evaluated the relationship between general and abdominal obesity, fat types, and indices of dietary fat quality amongst Ghanaian women. A separate assessment of the independent relationships between fatty acid types and obesity have largely failed to show significant associations, except that the total SFA intake only had a positive relationship with WC. In contrast, when the fatty acids were considered as indices, independent of other covariates, general obesity was inversely associated with $\sum \omega-3 / \sum \omega-6$ ratio and positively with TI and LI. Moreover, abdominal obesity had a positive association with AI, TI, LI, and TF. These associations support the proposition that compared with fat types, the dietary fatty acid indices may show a better relationship with health outcomes [30,32].

The intake of absolute amounts of dietary fatty acids appears not to have a consistent relationship with obesity. For instance, a previous observational study found no association between adiposity and the $\omega-3$ PUFA and SFA intake [14]. Also, another observational study found 
Table 3 Odds ratio $(95 \%$ Cl) of general and abdominal obesity according to quintiles (Q) of fat types

\begin{tabular}{|c|c|c|c|c|c|c|c|c|c|}
\hline \multirow[t]{2}{*}{ variable } & \multicolumn{3}{|l|}{ GO (no/yes) } & \multicolumn{3}{|c|}{$W C \geq 80 \mathrm{~cm}$ (no/yes) } & \multicolumn{3}{|c|}{ WHtR $\geq 0.50$ (no/yes) } \\
\hline & OR $(95 \% \mathrm{Cl})$ & P1 & $\overline{P 2}$ & OR $(95 \% \mathrm{Cl})$ & P1 & P2 & OR $(95 \% \mathrm{Cl})$ & P1 & $\mathrm{P} 2$ \\
\hline \multicolumn{10}{|l|}{ Total SFA } \\
\hline Q1 (55) & Reference & & & & & & & & \\
\hline \multirow[t]{2}{*}{ Q2 (56) } & $1.45(0.66-3.17)$ & & & $1.15(0.52-2.54)$ & & & $1.64(0.76-3.53)$ & & \\
\hline & $1.28(0.50-3.29)$ & & & $0.48(0.16-1.39)$ & & & $1.17(0.44-3.11)$ & & \\
\hline \multirow[t]{2}{*}{ Q3 (55) } & $0.76(0.33-1.75)$ & 0.02 & 0.2 & $0.76(0.33-1.76)$ & 0.002 & 0.02 & $0.77(0.35-1.74)$ & 0.01 & 0.09 \\
\hline & $0.56(0.18-1.71)$ & & & $0.14(0.04-0.51)$ & & & $0.29(0.09-0.97)$ & & \\
\hline \multirow[t]{2}{*}{ Q4 (56) } & $0.43(0.17-1.07)$ & & & $0.55(0.23-1.31)$ & & & $0.75(0.34-1.69)$ & & \\
\hline & $0.30(0.09-1.03)$ & & & $0.08(0.02-0.36)$ & & & $0.39(0.12-1.32)$ & & \\
\hline \multirow[t]{2}{*}{ Q5 (55) } & $2.16(0.99-4.70)$ & & & $2.49(1.14-5.44)$ & & & $2.64(1.22-5.71)$ & & \\
\hline & $1.41(0.53-3.78)$ & & & $1.07(0.37-3.12)$ & & & $1.42(0.50-3.99)$ & & \\
\hline \multicolumn{10}{|l|}{ Total PUFA } \\
\hline Q1 (55) & Reference & & & & & & & & \\
\hline \multirow[t]{2}{*}{ Q2 (56) } & $1.26(0.56-2.86)$ & & & $1.08(0.45-2.56)$ & & & $1.46(0.66-3.24)$ & & \\
\hline & $1.01(0.38-2.72)$ & & & $0.76(0.25-0.27)$ & & & $1.35(0.47-3.80)$ & & \\
\hline \multirow[t]{2}{*}{ Q3 (55) } & $1.30(0.57-2.94)$ & 0.7 & 0.4 & $1.45(0.62-3.37)$ & 0.01 & 0.5 & $1.63(0.74-3.59)$ & 0.050 & 0.7 \\
\hline & $0.77(0.26-2.82)$ & & & $0.76(0.24-2.42)$ & & & $0.99(0.32-3.06)$ & & \\
\hline \multirow[t]{2}{*}{ Q4 (56) } & $1.73(0.78-3.84)$ & & & $1.94(0.85-4.42)$ & & & $1.83(0.83-4.01)$ & & \\
\hline & $1.09(0.35-3.35)$ & & & $1.22(0.37-4.05)$ & & & $1.20(0.37-3.88)$ & & \\
\hline \multirow[t]{2}{*}{ Q5 (55) } & $1.09(0.48-2.51)$ & & & $2.69(1.19-6.10)$ & & & $2.19(0.25-1.18)$ & & \\
\hline & $0.50(0.12-2.00)$ & & & $1.29(0.31-5.40)$ & & & $1.41(0.34-5.81)$ & & \\
\hline \multicolumn{10}{|l|}{$\Sigma \omega-3$ PUFA } \\
\hline Q1 (55) & Reference & & & & & & & & \\
\hline \multirow[t]{2}{*}{ Q2 (39) } & $0.88(0.34-2.30)$ & & & $1.27(0.50-3.23)$ & & & $0.96(0.39-2.38)$ & & \\
\hline & $0.73(0.23-2.35)$ & & & $1.68(0.51-5.61)$ & & & $0.96(0.29-3.17)$ & & \\
\hline \multirow[t]{2}{*}{ Q3 (71) } & $2.14(0.99-4.62)$ & 0.1 & 0.1 & $2.10(0.96-4.60)$ & 0.1 & 0.3 & $1.68(0.80-3.56)$ & 0.6 & 0.2 \\
\hline & $3.00(1.14-7.94)$ & & & $3.23(1.13-9.24)$ & & & $2.63(0.94-7.41)$ & & \\
\hline \multirow[t]{2}{*}{ Q4 (52) } & $2.93(1.30-6.66)$ & & & $4.07(1.78-9.33)$ & & & $4.23(1.88-9.52)$ & & \\
\hline & $2.87(1.05-7.81)$ & & & $5.12(1.78-14.71)$ & & & $6.70(2.30-19.52)$ & & \\
\hline \multirow[t]{2}{*}{ Q5 (60) } & $0.59(0.24-1.46)$ & & & $0.57(0.22-1.46)$ & & & $1.22(0.55-2.69)$ & & \\
\hline & $0.60(0.20-1.80)$ & & & $0.84(0.26-2.76)$ & & & $2.10(0.71-6.20)$ & & \\
\hline \multicolumn{10}{|l|}{$\Sigma \omega-6$ PUFA } \\
\hline Q1 (58) & Reference & & & & & & & & \\
\hline \multirow[t]{2}{*}{ Q2 (47) } & $1.26(0.56-2.84)$ & & & $0.69(0.31-1.58)$ & & & $1.02(0.46-2.24)$ & & \\
\hline & $1.48(0.56-3.93)$ & & & $0.51(0.18-1.48)$ & & & $0.94(0.34-2.61)$ & & \\
\hline \multirow[t]{2}{*}{ Q3 (61) } & $1.17(0.54-2.51)$ & 0.2 & 0.8 & $0.74(0.35-1.58)$ & 0.3 & 0.5 & $0.92(0.44-1.94)$ & 0.08 & 0.2 \\
\hline & $1.5(0.61-3.74)$ & & & $0.84(0.33-2.17)$ & & & $1.26(0.49-3.21)$ & & \\
\hline \multirow[t]{2}{*}{ Q4 (56) } & $0.48(0.20-1.17)$ & & & $0.45(0.20-1.02)$ & & & $0.84(0.39-1.81)$ & & \\
\hline & $0.37(0.13-1.04)$ & & & $0.29(0.10-0.85)$ & & & $0.64(0.24-1.7)$ & & \\
\hline Q5 (55) & $1.60(0.74-3.46)$ & & & $1.18(0.55-2.50)$ & & & $1.70(0.80-3.59)$ & & \\
\hline & $1.27(0.51-3.16)$ & & & $1.01(0.39-2.63)$ & & & $1.65(0.64-4.28)$ & & \\
\hline
\end{tabular}

P1: unadjusted; P2: adjusted for age (continuous); asset score (continuous); physical activity level (natural log transformed); dietary energy/kcal (continuous); woman education (categorical); husband education (categorical); occupation woman (categorical); occupation husband (categorical); marital status (categorical). In the multiple regression models, dummy variables were created for categorical covariates. TF; percentage of energy obtained from dietary fat. P; Test of linear trends across quintiles of SFA, PUFAs, $\Sigma \omega-3$, and $\Sigma \omega-6$ were calculated for the models assessing chance of overweight/obesity as measured by body mass index, waist circumference and waist circumference to height ratio. To analyze these linear trends, the median values of total SFA, PUFAs, $\Sigma \omega-3$, and $\Sigma \omega-6$ were imputed for each quintile and the new variables were treated as continuous variables. All tests statistics are considered significant for $\mathrm{P}<0.05$, OR Odds ratio, Cl Confidence Interval, GO General obesity, WC waist circumference, WHtR waist to height ratio, SFA Saturated fatty acids, PUFA Polyunsaturated fatty acids, $\Sigma \omega-3$; Summation of omega-3 polyunsaturated fatty acids, $\Sigma \omega-6$; Summation of omega- 6 polyunsaturated fatty acids 
Table 4 odds ratio $(95 \% \mathrm{Cl})$ of general and abdominal obesity according to quintiles (Q) of fat quality indices

\begin{tabular}{|c|c|c|c|c|c|c|c|c|c|}
\hline \multirow[t]{2}{*}{ variable } & \multicolumn{3}{|l|}{ GO (no/yes) } & \multicolumn{3}{|c|}{$W C \geq 80 \mathrm{~cm}$ (no/yes) } & \multicolumn{3}{|c|}{$\mathrm{WHtR} \geq 0.50$ (no/yes) } \\
\hline & OR $(95 \% \mathrm{Cl})$ & P1 & $\mathrm{P} 2$ & OR $(95 \% \mathrm{Cl})$ & P1 & $\mathrm{P} 2$ & OR $(95 \% \mathrm{Cl})$ & P1 & P2 \\
\hline \multicolumn{10}{|l|}{ PSR } \\
\hline Q1(55) & Reference & & & & & & & & \\
\hline \multirow[t]{2}{*}{ Q2 (56) } & $0.25(0.11-0.59)$ & & & $0.15(0.06-0.37)$ & & & $0.26(0.12-0.58)$ & & \\
\hline & $0.26(0.09-0.72)$ & & & $0.08(0.02-0.29)$ & & & $0.24(0.08-0.69)$ & & \\
\hline \multirow[t]{2}{*}{ Q3 } & $0.26(0.11-0.60)$ & 0.3 & 0.7 & $2.00(0.08-0.47)$ & 0.3 & 0.6 & $0.44(0.21-0.95)$ & 0.2 & 0.3 \\
\hline & $0.20(0.07-0.54)$ & & & $0.07(0.02-0.24)$ & & & $0.30(0.11-0.80)$ & & \\
\hline \multirow[t]{2}{*}{ Q4 } & $0.62(0.29-1.33)$ & & & $0.72(0.34-1.53)$ & & & $0.67(0.32-1.42)$ & & \\
\hline & $0.75(0.29-1.89)$ & & & $0.81(0.30-2.21)$ & & & $0.74(0.28-1.92)$ & & \\
\hline \multirow[t]{2}{*}{ Q5 } & $0.55(0.25-1.18)$ & & & $0.44(0.20-0.95)$ & & & $0.37(0.17-0.82)$ & & \\
\hline & $0.73(0.28-1.90)$ & & & $0.49(0.18-1.40)$ & & & $0.42(0.15-1.16)$ & & \\
\hline \multicolumn{10}{|l|}{$\sum \omega-3 / \Sigma \omega-6$} \\
\hline Q1 (55) & Reference & & & & & & & & \\
\hline \multirow[t]{2}{*}{ Q2 (56) } & $2.42(1.07-5.48)$ & & & $3.13(1.31-7.46)$ & & & $2.68(1.17-6.16)$ & & \\
\hline & $3.81(1.22-11.87)$ & & & $3.11(0.91-10.70)$ & & & $4.42(1.31-14.97)$ & & \\
\hline \multirow[t]{2}{*}{ Q3 (55) } & $1.65(0.72-3.81)$ & 0.01 & 0.005 & $2.13(0.87-5.16)$ & 0.08 & 0.02 & $2.15(0.93-4.97)$ & 0.9 & 0.8 \\
\hline & $3.03(0.82-11.14)$ & & & $1.89(0.46-7.74)$ & & & $5.33(1.34-21.12)$ & & \\
\hline \multirow[t]{2}{*}{ Q4 (56) } & $2.50(1.10-5.67)$ & & & $5.01(2.11-11.93)$ & & & $5.37(2.32-12.41)$ & & \\
\hline & $3.39(0.84-13.68)$ & & & $3.14(0.70-14.15)$ & & & $9.28(2.10-40.99)$ & & \\
\hline \multirow[t]{2}{*}{ Q5 (55) } & $0.63(0.24-1.63)$ & & & $1.00(0.37-2.63)$ & & & $1.89(0.81-4.41)$ & & \\
\hline & $0.79(0.22-2.81)$ & & & $0.73(0.18-3.02)$ & & & 3.59(0.99-12.99) & & \\
\hline \multicolumn{10}{|l|}{$h / H$} \\
\hline Q1 (55) & Reference & & & & & & & & \\
\hline \multirow[t]{2}{*}{ Q2 (56) } & $0.13(0.05-0.35)$ & & & $0.13(0.05-0.35)$ & & & $0.28(0.13-0.63)$ & & \\
\hline & $0.13(0.04-0.40)$ & & & $0.11(0.03-0.35)$ & & & $0.27(0.10-0.75)$ & & \\
\hline \multirow[t]{2}{*}{ Q3 (55) } & $0.50(0.23-1.09)$ & 0.4 & 0.4 & $0.50(0.23-1.09)$ & 0.6 & 0.3 & $0.51(0.24-1.10)$ & 0.03 & 0.01 \\
\hline & $0.59(0.23-1.49)$ & & & $0.46(0.17-1.24)$ & & & $0.53(0.20-1.42)$ & & \\
\hline \multirow[t]{2}{*}{ Q4 (56) } & $0.45(0.21-0.98)$ & & & $0.45(0.21-0.98)$ & & & $0.46(0.21-0.99)$ & & \\
\hline & $0.55(0.22-1.40)$ & & & $0.31(0.11-0.87)$ & & & $0.39(0.14-1.06)$ & & \\
\hline \multirow[t]{2}{*}{ Q5 (55) } & $0.43(0.19-0.94)$ & & & $0.46(0.21-1.01)$ & & & $0.29(0.13-0.65)$ & & \\
\hline & $0.38(0.15-0.99)$ & & & $0.39(0.14-1.06)$ & & & $0.20(0.07-0.56)$ & & \\
\hline \multicolumn{10}{|l|}{ Al } \\
\hline Q1 (55) & Reference & & & & & & & & \\
\hline \multirow[t]{2}{*}{ Q2 (56) } & $1.23(0.57-2.69)$ & & & $1.24(0.56-2.74)$ & & & 1.68(0.77-3.65) & & \\
\hline & $1.89(0.68-5.14)$ & & & $1.21(0.41-3.54)$ & & & $2.55(0.88-7.46)$ & & \\
\hline \multirow[t]{2}{*}{ Q3 (55) } & $0.70(0.31-1.61)$ & 0.03 & 0.1 & $0.92(0.41-2.07)$ & 0.008 & 0.01 & $1.61(0.73-3.52)$ & 0.01 & 0.04 \\
\hline & $0.20(0.37-2.68)$ & & & $1.12(0.40-3.15)$ & & & $2.58(0.94-7.14)$ & & \\
\hline Q4 (56) & $0.39(0.16-0.97)$ & & & $0.37(0.15-0.96)$ & & & $0.75(0.32-1.71)$ & & \\
\hline & $0.40(0.13-1.19)$ & & & $0.27(0.08-0.93)$ & & & $0.99(0.33-3.00)$ & & \\
\hline Q5 (55) & $1.98(0.91-4.29)$ & & & $1.24(0.56-2.74)$ & & & $2.89(1.32-6.31)$ & & \\
\hline & $2.43(0.92-6.42)$ & & & $2.30(1.07-8.38)$ & & & $4.17(1.45-11.99)$ & & \\
\hline $\mathrm{TI}$ & & & & & & & & & \\
\hline Q1 (55) & Reference & & & & & & & & \\
\hline Q2 (56) & $2.58(1.10-6.06)$ & & & $2.78(1.19-6.51)$ & & & $1.54(0.71-3.33)$ & & \\
\hline
\end{tabular}


Table 4 odds ratio $(95 \% \mathrm{Cl})$ of general and abdominal obesity according to quintiles (Q) of fat quality indices (Continued)

\begin{tabular}{|c|c|c|c|c|c|c|c|c|c|}
\hline \multirow[t]{2}{*}{ variable } & \multicolumn{3}{|l|}{ GO (no/yes) } & \multicolumn{3}{|c|}{$W C \geq 80 \mathrm{~cm}$ (no/yes) } & \multicolumn{3}{|c|}{$\mathrm{WHtR} \geq 0.50$ (no/yes) } \\
\hline & $\overline{\mathrm{OR}}(95 \% \mathrm{Cl})$ & P1 & $\mathrm{P} 2$ & OR $(95 \% \mathrm{Cl})$ & $\mathrm{P} 1$ & P2 & OR $(95 \% \mathrm{Cl})$ & P1 & P2 \\
\hline & $2.76(1.07-7.16)$ & & & $(2.580 .96-6.93)$ & & & $1.71(0.68-4.31)$ & & \\
\hline \multirow[t]{2}{*}{ Q3 (55) } & $1.64(0.68-3.95)$ & 0.003 & 0.01 & $1.50(0.61-3.64)$ & 0.004 & 0.009 & $1.17(0.53-2.58)$ & 0.02 & 0.03 \\
\hline & $1.69(0.62-4.65)$ & & & $1.24(0.41-3.76)$ & & & $1.03(0.38-2.79)$ & & \\
\hline \multirow[t]{2}{*}{ Q4 (56) } & $1.09(0.43-2.73)$ & & & $1.20(0.48-2.99)$ & & & $0.82(0.36-1.84)$ & & \\
\hline & $1.44(0.48-4.29)$ & & & $1.10(0.35-3.48)$ & & & $0.82(0.29-2.38)$ & & \\
\hline \multirow[t]{2}{*}{ Q5 (55) } & $4.14(1.78-9.66)$ & & & $4.14(1.78-9.66)$ & & & $2.65(1.22-5.76)$ & & \\
\hline & $4.93(1.74-13.95)$ & & & 4.85(1.62-14.49) & & & $3.01(1.08-8.39)$ & & \\
\hline \multicolumn{10}{|l|}{ LI } \\
\hline Q1 (55) & Reference & & & & & & & & \\
\hline \multirow[t]{2}{*}{ Q2 (56) } & $0.97(0.43-2.18)$ & & & $0.89(0.40-1.97)$ & & & $1.54(0.71-3.33)$ & & \\
\hline & $1.36(0.54-3.44)$ & & & $1.71(0.64-4.52)$ & & & $2.74(1.04-7.20)$ & & \\
\hline \multirow[t]{2}{*}{ Q3 (55) } & $0.91(0.40-2.07)$ & 0.006 & 0.01 & $0.71(0.31-1.60)$ & 0.01 & 0.02 & $1.17(0.53-2.58)$ & 0.004 & 0.007 \\
\hline & $1.30(0.51-3.32)$ & & & $0.86(0.31-2.36)$ & & & $1.90(0.72-5.07)$ & & \\
\hline \multirow[t]{2}{*}{ Q4 (56) } & $0.48(0.19-1.18)$ & & & $0.36(0.14-0.89)$ & & & $0.62(0.26-1.43)$ & & \\
\hline & $0.60(0.21-1.71)$ & & & $0.28(0.09-0.92)$ & & & $0.60(0.20-1.85)$ & & \\
\hline \multirow[t]{2}{*}{ Q5 (55) } & $2.49(1.14-5.43)$ & & & $2.11(0.98-4.55)$ & & & $3.32(1.52-7.28)$ & & \\
\hline & $3.26(1.27-8.39)$ & & & $3.26(1.20-8.83)$ & & & $5.81(2.06-16.41)$ & & \\
\hline \multicolumn{10}{|l|}{ PSR } \\
\hline Q1(55) & Reference & & & & & & & & \\
\hline \multirow[t]{2}{*}{ Q2 (56) } & $1.35(0.61-3.01)$ & & & $0.97(0.44-2.16)$ & & & $1.32(0.61-2.85)$ & & \\
\hline & $1.48(0.57-3.84)$ & & & $1.22(0.44-3.36)$ & & & $1.20(0.74-5.39)$ & & \\
\hline \multirow[t]{2}{*}{ Q3 } & $0.91(0.40-2.10)$ & 0.08 & 0.06 & $1.09(0.49-2.39)$ & 0.2 & 0.003 & $1.08(0.50-2.37)$ & 0.1 & 0.009 \\
\hline & $0.97(0.36-2.64)$ & & & $1.58(0.56-4.43)$ & & & $1.55(0.56-4.33)$ & & \\
\hline \multirow[t]{2}{*}{ Q4 } & $0.73(0.32-1.73)$ & & & $0.50(0.21-1.20)$ & & & $1.05(0.48-2.30)$ & & \\
\hline & $0.75(0.26-2.15)$ & & & $0.75(0.24-2.38)$ & & & $1.87(0.63-5.54)$ & & \\
\hline \multirow[t]{2}{*}{ Q5 } & $2.03(0.92-4.47)$ & & & $1.59(0.73-3.46)$ & & & $1.83(0.85-3.93)$ & & \\
\hline & $2.54(0.91-7.04)$ & & & $4.71(1.57-14.10)$ & & & $4.44(1.52-13.00)$ & & \\
\hline
\end{tabular}

P1: unadjusted; P2: adjusted for age (continuous); asset score (continuous); physical activity level (natural log transformed); dietary energy/kcal (continuous); woman education (categorical); husband education (categorical); occupation woman (categorical); occupation husband (categorical); marital status (categorical). In the multiple regression models, dummy variables were created for categorical covariates. $\mathrm{P}$; Tests of linear trend across increasing PSR, $\Sigma \omega-3 / \Sigma \omega-6, h / H, A l, T I, L I$ and TF were calculated for the models assessing chance of overweight/obesity as measured by body mass index, waist circumference and waist circumference to height ratio. To analyze these linear trends, the median values of PSR, $\Sigma \omega-3 / \Sigma \omega-6, \mathrm{~h} / \mathrm{H}, \mathrm{Al}, \mathrm{Tl}, \mathrm{LI}$ and TF were imputed for each quintile and the new variables were treated as continuous variables. All tests statistics are considered significant for $\mathrm{P}<0.05$, OR Odds ratio, $\mathrm{Cl}$ Confidence Interval, $G O \mathrm{General}$ obesity (BMI $\geq 25), W C$ waist circumference, $W H t R$ waist to height ratio, PSR polyunsaturated to saturated fatty acids ratio, $\Sigma \omega-3 / \Sigma \omega-6$; omega-3 to omega- 6 fatty acids ratio, $h / H$ hypo and hypercholesterolemic ratio, Al Atherogenicity index, TI Thrombogenic index, LI Dietary lipophilic index, TF Percentage of energy from total fat

an inverse association between dietary SFA and WC after adjustment for age. However, this association was no longer significant after an additional adjustment for BMI [46].

Unlike the present study, in which the prevalence of obesity was evaluated in association with dietary fatty acids in the form of indices, most previous studies in Ghana only assessed associations between type of cooking fats and oils [23, 47] and quantity of dietary fat [27] in relation to obesity. Of these studies, no significant association was found between obesity and types of cooking fat and oil [23, 47]. These studies are limited in their capacity to reveal the relative proportions of dietary fatty acids that are consumed, therefore, they may not be able to inform nutrition policy formulation. Moreover, dietary energy intake was not adjusted in these studies.

There was an inverse association between general obesity and WC with $\Sigma \omega-3 / \Sigma \omega-6$ ratio in the present study. Contrary, Lund et al. [19] in the Danish cohort study, found non-significant associations between $\sum \omega-3 /$ $\Sigma \omega-6$ ratio and WC and BMI. The disparity between our findings and Lund et al. study might be explained by the differences in study design, sample size and characteristics of study participants. Results from cross-sectional 
studies in Alabama [20] and Algeria [18] showed inverse associations between $\sum \omega-6 / \sum \omega-3$ ratios and obesity. In contrast, this argues against the present study results and also the findings from a review [48], in which the author clearly reported that a higher ratio of $\sum \omega-6 / \Sigma \omega-3$ increases the risk of obesity.

In the present study, there was a positive association between TF and abdominal obesity. In contrast to our observation, two previous cross-sectional studies from Ghana reported inverse associations between the percentage of energy obtained from total fat and overweight/obesity $[16,49]$. However, Mogre et al. showed a weak inverse association between the absolute quantity of dietary fat intake and both WC and BMI among University students [27]. The reasons for the disparity between the present findings and these earlier studies are not understood, however, differences in the study settings may have partly introduced the variations in the results. Moreover, a setback in those earlier studies was that the effect of total energy intake was not adjusted in the analysis.

In the present study, the findings revealed a positive relationship between TI and LI and a chance for both general and abdominal obesity as well as a positive association between AI and TF and abdominal obesity. It is not entirely understood what accounted for the positive associations observed between obesity and the above DFQ indices, however, it might have resulted from the cumulative contributions of palmitic, myristic and stearic acids and possibly the activities of linoleic acid (LA). This is because higher values of AI, TI and LI favor greater intakes of palmitic, myristic and stearic acids [30, 32], which are linked to increased risk of obesity [14].

Higher intake of PSR was found to associate inversely with general and abdominal obesity although this observation did not attain statistical significance. The present findings compare partly with the results of two prospective studies [12, 18], in which Phillips and colleagues [12] showed that, low dietary PUFA:SFA ratio at baseline significantly associated with increased risk of both general and abdominal obesity whereas, low dietary PUFA:SFA ratio at follow-up only significantly related with higher increased risk of general obesity but showed nonsignificant positive association with abdominal obesity. Another prospective study from Africa [18] revealed lower intake of unsaturated fatty acids to SFA ratio in overweight/obese T2DM subjects and overweight/obese subjects without T2DM compared with T2DM of normal weight.

Although the mechanisms involved in the association of fatty acids and obesity are not clear, there is evidence that long-chain omega fatty acids have the capacity to suppress appetite while prolonging satiety [50]. Their ingestion also influences gene expressions in various organs that suppress fat deposition, cause an increase in both $\beta$-oxidation and energy expenditure [51, 52]. Similarly, the medium chain fatty acids are said to cause increased fat oxidation and energy expenditure [53, 54]. On the other hand, higher intake of long-chain SFAs such as myristic, palmitic and stearic acids tend to favor higher values of LI, AI and TI [31, 32]. They have the ability to influence gene expressions in various organs more especially fat mass and obesity-associated gene and signal transducer and activator of transcription 3 gene polymorphisms $[12,13,55]$, thereby, increasing the risk of obesity. Similarly, high $\omega-6$ fatty acids intake may promote the development of obesity. For instance, evidence from animal studies suggested that when linoleic acid is converted to arachidonic acid, it has the capacity to engineer body weight gain and adipogenesis partly through the prostacyclin pathway [56].

\section{Strengths and limitations}

The present study has important strengths. First, we adjusted for the effects of total energy intake and other important confounding variables in order to estimate independent associations between fat indices and obesity. Second, as far as we know, this was the first study to investigate DFQ in such a broader form and its relationship with general and abdominal obesity in Ghana; this may serve as precedence for other researchers. Despite these strengths, the study has some limitations. First, the sample size was small. Second, due to the cross-sectional design of the study, our findings do not proclaim a causal relationship between fat indices and obesity/overweight. Therefore, the present results ought to be interpreted with great caution. Third, dietary intake assessment was based on recalls thus, a chance for misreporting of food items cannot be ruled out completely. Moreover, despite the fact that we adjusted for the effects of dietary energy and other important potential confounders, residual confounding cannot be ruled out. Moreover, the study duration was short. Hence, we cannot discount seasonal effects on food intake.

\section{Conclusion}

The present study revealed an inverse association between $\Sigma \omega-3 / \sum \omega-6$ ratio, and general obesity and WC. Furthermore, abdominal obesity showed a positive association with AI and TF. Additionally, both general and abdominal obesity had positive relationships with TI and LI. Therefore, dietary advice in favor of an increased higher ratio of $\sum \omega-3 / \sum \omega-6$, and a lower intake of AI, LI, and TF may be useful for obesity prevention. The effect of fat quality on obesity should be further studied using an experimental design. 


\section{Abbreviations}

DFQ: Dietary fat quality; PSR: Polyunsaturated to saturated fatty acids ratio; h/ $\mathrm{H}$ : Hypo and hypercholesterolemic ratio; Al: Atherogenicity index; TI: Thrombogenic index; LI: Lipophilic index; TF: Percentage of energy from total fat; T2DM: Type 2 diabetes mellitus; MET-minutes/weeks: Metabolic equivalent minutes per week; 12:0: Lauric acid; 14:0: Myristic acid; 16:0: Palmitic acid; 18:0: Stearic acid; 18:1 $\omega$-9: Oleic acid; 18:2 $\omega-6$ : Linoleic acid; 20:4 $\omega-6$ : Arachidonic acid; 18:3 $\omega$-3: Alpha-linolenic acid; 20:5 $\omega-$ 3: Eicosapentaenoic acid; 22:5 $\omega$-3: Docosapentaenoic acid; 22:6 $\omega$ 3: Docosahexaenoic acid; MUFA: Monounsaturated fatty acids; PUFA: Polyunsaturated fatty acids; SFAs: Saturated fatty acids; $\Sigma \omega-6$ PUFA: Sum of omega- 6 polyunsaturated fatty acids; $\sum \omega-3$ PUFA: Sum of omega-3 polyunsaturated fatty acids; $\mathrm{kcal} / \mathrm{d}$ : kilocalories per day; Qs: Quintiles; BMI: Body Mass Index; WC: Waist circumference; WHtR: Waist to Height Ratio; OR: Odds ratio; P: Statistical significance level for trend test; SDs: Means \pm standard deviations; Cls: Confidence intervals; LA: Linoleic acid

\section{Acknowledgments}

We are thankful to all participants of the study and the International Campus of Tehran University of Medical Sciences.

\section{Authors' contributions}

SBS has made substantial contributions to conception and design and has been involved in drafting of the manuscript. SA has made valuable contribution to the conception and drafting of the manuscript. GS has made substantial contributions to the design, revised the manuscript critically and given final approval of the version to be submitted. MS has made substantial contributions to conception and revised the manuscript. FS has made substantial contribution to conception and design and revised the manuscript critically. ARF has contributed to conception and design and in offering advice on statistical design and analysis.

\section{Funding}

This project was supported by the International Campus of Tehran University of Medical Sciences under grant number 9513475002.

\section{Availability of data and materials}

The datasets used to support the findings of this study are available from the corresponding author upon request.

\section{Ethics approval and consent to participate}

The study was carried out in line with the Declaration of Helsinki. All study participants provided written informed consent. The study was approved by two ethics committees [(first, the Ethics Committee of Tehran University of Medical Sciences, Tehran, Iran (IR.TUMS.VCR.REC.1397.4928); second, the Ethics Review Committee of Tamale Teaching Hospital, Tamale, Ghana (TTHERC.19/06/18/02)].

\section{Consent for publication}

Not applicable.

\section{Competing interests}

The authors declare that they have no competing interests.

\begin{abstract}
Author details
${ }^{1}$ Department of Community Nutrition, School of Nutritional Sciences and Dietetics, International Campus, Tehran University of Medical Sciences, Number 21, Dameshgh St. Vali-e Asr Ave., Tehran 1416753955, Iran. ${ }^{2}$ Department of Community Nutrition, School of Nutritional Sciences and Dietetics, Tehran University of Medical Sciences, Hojatdost street, Naderi street, Keshavarz Blv, Tehran, Iran. ${ }^{3}$ Department of Nutritional Sciences, School of Allied Health Sciences, University for Development Studies, Post Office Box 1350, Tamale, Ghana. ${ }^{4}$ Department of Statistics and Epidemiology, School of Public Health, Tehran University of Medical Sciences, Tehran, Iran.
\end{abstract}

Received: 12 December 2019 Accepted: 9 March 2020 Published online: 11 April 2020

\section{References}

1. Kelly T, Yang W, Chen CS, Reynolds K, He J. Global burden of obesity in 2005 and projections to 2030. Int J Obes. 2008;32:1431-7.
2. Stevens GA, Singh GM, Lu Y, Danaei G, Lin JK, Finucane MM, et al. National, regional, and global trends in adult overweight and obesity prevalences. Popul health Metr. 2012;10:1 Available from: Population Health Metrics.

3. Ofori-Asenso R, Agyeman AA, Laar A, Boateng D. Overweight and obesity epidemic in Ghana - a systematic review and meta-analysis. BMC public health [internet]. BMC Public Health. 2016;16. Available from:. https://doi org/10.1186/s12889-016-3901-4

4. Ozcan Dag Z, Dilbaz B. Impact of obesity on infertility in women. J Turkish Ger Gynecol Assoc [Internet]. 2015;16:111-7 Available from: http://cms. galenos.com.tr/Uploads/Article_13433/111-7.pdf.

5. Calhoun KC. Obesity and infertility. Obes Dur Pregnancy Clin Pract. 2014:1131. https://doi.org/10.1007/978-1-4471-2831-1_2.

6. Alberti KGMM, Eckel RH, Grundy SM, Zimmet PZ, Cleeman JI, Donato KA, et al. Harmonizing the metabolic syndrome. Circulation. 2009;120:1640-5. https://doi.org/10.1161/CIRCULATIONAHA.109.192644.

7. Grundy SM. Metabolic syndrome update. Trends Cardiovasc Med [Internet]. 2016;26:364-73 Available from: https://linkinghub.elsevier.com/retrieve/pii/ S1050173815002492

8. Singh GM, Danaei G, Farzadfar F, Stevens GA, Woodward M, Wormser D, et al. The Age-Specific Quantitative Effects of Metabolic Risk Factors on Cardiovascular Diseases and Diabetes: A Pooled Analysis. Wang G, editor. PLoS One. 2013;8:e65174. https://doi.org/10.1371/journal.pone.0065174.

9. Lauby-Secretan B, Scoccianti C, Loomis D, Grosse Y, Bianchini F, Straif K. Body fatness and Cancer - viewpoint of the IARC working group. N Engl J Med. 2016;375:794-8. https://doi.org/10.1056/NEJMsr1606602.

10. Jiang $L$, Rong J, Wang Y, Hu F, Bao C, Li X, et al. The relationship between body mass index and hip osteoarthritis: A systematic review and metaanalysis. Jt. Bone Spine. 2011:78(2):150-5.

11. Jiang L, Tian W, Wang Y, Rong J, Bao C, Liu Y, et al. Body mass index and susceptibility to knee osteoarthritis: a systematic review and meta-analysis. Jt Bone Spine. 2012;79:291-7.

12. Phillips CM, Kesse-Guyot E, McManus R, Hercberg S, Lairon D, Planells R, et al. High dietary saturated fat intake accentuates obesity risk associated with the fat mass and obesity-associated gene in adults. J Nutr. 2012;142: 824-31.

13. Moleres A, Ochoa MC, Rendo-Urteaga T, Martínez-González MA, Azcona San Julián MC, Martínez JA, et al. Dietary fatty acid distribution modifies obesity risk linked to the rs9939609 polymorphism of the fat mass and obesityassociated gene in a Spanish case-control study of children. Br J Nutr. 2012; 107:533-8.

14. Raatz S, Conrad Z, Johnson L, Picklo M, Jahns L. Relationship of the Reported Intakes of Fat and Fatty Acids to Body Weight in US Adults. Nutrients. 2017;9: 438 Available from: http://www.mdpi.com/2072-6643/9/5/438.

15. Youssef MM, Mohsen MA, El-soud NHA, Kazem YA. Energy Intake, Diet Composition among Low Social Class Overweight and Obese Egyptian Adolescents. J Am Sci. 2010;6:160-8.

16. Pereko KKA, Setorglo J, Owusu WB, Tiweh JM, Achampong EK. Overnutrition and associated factors among adults aged 20 years and above in fishing communities in the urban Cape Coast Metropolis. Ghana Public Health Nutr. 2013;16:591-5.

17. Forouhi NG, Sharp SJ, Du H, Van Der ADL, Halkjær J, Schulze MB, et al. Dietary fat intake and subsequent weight change in adults: results from the European prospective investigation into Cancer and nutrition cohorts. Am J Clin Nutr. 2009;90:1632-41.

18. Diaf M, Khaled MB, Sellam F. Correlation between dietary fat intake and atherogenic indices in normal, overweight and obese adults with or without type 2 diabetes. Rom J Diabetes, Nutr Metab Dis. 2015;22:347-60..

19. Lund ASQ, Hasselbalch AL, Gamborg M, Skogstrand K, Hougaard DM, Heitmann BL, et al. N-3 polyunsaturated fatty acids, body fat and inflammation. Obes Facts. 2013;6:369-79.

20. Cardel M, Lemas DJ, Jackson KH, Friedman JE, Fernández JR. Higher intake of PUFAs is associated with lower Total and visceral adiposity and higher lean mass in a racially diverse sample of children. J Nutr. 2015;145:2146-52.

21. Nimptsch K, Berg-Beckhoff G, Linseisen J. Effect of dietary fatty acid intake on prospective weight change in the Heidelberg cohort of the European prospective investigation into Cancer and nutrition. Public Health Nutr. 2010;13:1636-46.

22. Galbete C, Nicolaou M, Meeks K, Klipstein-Grobusch K, De-Graft Aikins A Addo J, et al. Dietary patterns and type 2 diabetes among Ghanaian migrants in Europe and their compatriots in Ghana: the RODAM study. Nutr Diabetes. 2018;8(1):25. http://www.nature.com/articles/s41387-018-0029-x. 
23. Mogre V, Mwinlenaa PP, Oladele J, Amalba A. Impact of physical activity levels and diet on central obesity among civil servants in Tamale metropolis. J Med Biomed Sci. 2012;1(2):1-9.

24. Montoya C, Cochard B, Flori A, Cros D, Lopes R, Cuellar T, et al. Genetic Architecture of Palm Oil Fatty Acid Composition in Cultivated Oil Palm (Elaeis guineensis Jacq.) Compared to Its Wild Relative E. oleifera (H.B.K) Cortés. Wu R, editor. PLoS One [Internet]. 2014;9(5):e95412.

25. Sambanthamurthi R, Sundram K, Tan YA. Chemistry and biochemistry of palm oil. Prog. Lipid Res. 2000:507-58.

26. Adomako D. Fatty acid composition and characteristics of Pentadesma butyracea fat extracted from Ghana seeds. J Sci Food Agric. 1977;28:384-6.

27. Mogre V, Nyaba R, Aleyira S, Sam NB. Demographic, dietary and physical activity predictors of general and abdominal obesity among university students: a cross-sectional study. Springerplus. 2015;4(1):226. Available from: https://springerplus.springeropen.com/articles/10.1186/s40064-015-0999.

28. Mendez MA, Covas MI, Marrugat J, Vila J, Schröder H. Glycemic load, glycemic index, and body mass index in Spanish adults. Am J Clin Nutr. 2009;89:316-22 Available from: https://academic.oup.com/ajcn/article/ 89/1/316/4598258

29. Lau C, Toft U, Tetens I, Richelsen B, Jørgensen T, Borch-Johnsen K, et al. Association between dietary glycemic index, glycemic load, and body mass index in the Inter99 study: is underreporting a problem? Am J Clin Nutr. 2006;84:641-5.

30. Ulbricht TLV, Southgate DAT. Coronary heart disease: seven dietary factors. Lancet. 1991;338:985-92.

31. Santos-Silva J, Bessa RJB, Santos-Silva F. Effect of genotype, feeding system and slaughter weight on the quality of light lambs. II. Fatty acid composition of meat. Livest Prod Sci. 2002;77:187-94.

32. Ding EL, Sun Q, Campos H, Hu FB. Lipophilic Index of Fatty Acid Fluidity in Erythrocyte and Plasma and Risk of Coronary Heart Disease. Circulation. 2008;118:S_1089.

33. Barbieiri $P$, Nunes JC, Torres AG, Nishimura RY, Zuccolotto DCC, Crivellenti LC, et al. Indices of dietary fat quality during midpregnancy is associated with gestational diabetes. Nutrition. Elsevier Inc. 2016;32:656-61.

34. Toledo E, Campos H, Ding EL, Wu H, Hu FB, Sun Q, et al. A novel fatty acid profile index-the lipophilic index-and risk of myocardial infarction. Am J Epidemiol. 2013;178:392-400.

35. Sesti G, Folli F, Perego L, Hribal ML, Pontiroli AE. Effects of Weight Loss in Metabolically Healthy Obese Subjects after Laparoscopic Adjustable Gastric Banding and Hypocaloric Diet. Fadini GP, editor. PLoS One, 2011;6:e17737. https://doi.org/10.1371/journal.pone.0017737.

36. Rosner B. Fundamentals of biostatistics, 6 edition. 6 th ed. Belmont, Calif. USA: Brooks/Cole Publishing Co; 2006.

37. World Health Organization. Obesity: preventing and managing the global epidemic. In: Report of a WHO Consultation. World Health Organ Tech Rep Ser. Who; 2000. p. 1-253.

38. Waist circumference and waist-hip ratio.Report of a WHO expert consultation, Geneva, 8-11 December 2008. http://www.who.int/nutrition/ publications/obesity/WHO_report_waistcircumference_and_waisthip_ratio/ en/. Publication date: 2011.

39. Ashwell M, Hsieh SD. Six reasons why the waist-to-height ratio is a rapid and effective global indicator for health risks of obesity and how its use could simplify the international public health message on obesity. Int J Food Sci Nutr. 2005;56:303-7.

40. Craig CL, Marshall AL, Sjöström M, Bauman AE, Booth ML, Ainsworth BE, Pratt M, Ekelund U, Yngve A, Sallis JF, Oja P. International Physical Activity Questionnaire: 12-Country Reliability and Validity. Med Sci Sports Exerc. 2003;35(8):1381-1395.

41. Craig $C L$, Marshall AL, Sjöström M, Bauman AE, Booth ML, Ainsworth BE, et al. International physical activity questionnaire: 12-country reliability and validity. Med Sci Sports Exerc. 2003;35:1381-95.

42. USDA. United States Department of Agriculture (USDA) food Composition Databases [Internet]. [cited 2018 Oct 17]. Available from: https://ndb.nal. usda.gov/ndb/nutrients/index.

43. Japanese Lipid Bank [Internet]. Available from: http://lipidbank.jp/cgi-bin/ main.cgi?id=ALL. Accessed Aug 2018.

44. Willett W. Issues in Analysis and Presentation of Dietary Data. Nutr Epidemiol. 2nd ed. New York: Oxford University Press; 1998. p. 321-46. https://doi.org/10.1093/acprof:oso/9780195122978.001.0001/acprof9780195122978-chapter-13

45. Willett WSM. Total energy intake: implications for epidemiologic analyses. Am J Epidemiol. 1986;124:17-27.
46. Noel SE, Newby PK, Ordovas JM, Tucker KL. Adherence to an (n-3) Fatty Acid/ Fish Intake Pattern Is Inversely Associated with Metabolic Syndrome among Puerto Rican Adults in the Greater Boston Area. J Nutr. 2010;140:1846-54 Available from: https://academic.oup.com/jn/article/140/10/1846/4689087.

47. Duda R, Darko R, Seffah J, Adanu R, Anarfi J, Hill A. Prevalence of Obesity in Women of Accra, Ghana. Afr J Health Sci [Internet]. 2008;14 (3-4):154-159.

48. Simopoulos A. An Increase in the Omega-6/Omega-3 Fatty Acid Ratio Increases the Risk for Obesity. Nutrients. 2016;8:128 Available from: http:// www.mdpi.com/2072-6643/8/3/128.

49. Appiah CA, Steiner-Asiedu M, Otoo GE. Predictors of overweight/obesity in urban Ghanaian women. Int J Clin Nutr. 2014;2:60-8 Available from: http:// pubs.sciepub.com/ijcn/2/3/3

50. Parra D, Ramel A, Bandarra N, Kiely M, Martínez JA, Thorsdottir I. A diet rich in long chain omega-3 fatty acids modulates satiety in overweight and obese volunteers during weight loss. Appetite. 2008:51:676-80.

51. Couet C, Delarue J, Ritz P, Antoine JM, Lamisse F. Effect of dietary fish oil on body fat mass and basal fat oxidation in healthy adults. Int J Obes. 1997;21: 637-43.

52. Ukropec J, Reseland JE, Gasperikova D, Demcakova E, Madsen L, Berge RK, et al. The Hypotriglyceridemic effect of dietary n-3 FA is associated with increased $\beta$-oxidation and reduced Leptin expression. Lipids. 2003;38:1023-9.

53. Clegg ME. Medium-chain triglycerides are advantageous in promoting weight loss although not beneficial to exercise performance. Int J Food Sci Nutr. 2010;61:653-79.

54. Mumme K, Stonehouse W. Effects of medium-chain triglycerides on weight loss and body composition: a meta-analysis of randomized controlled trials. J Acad Nutr Diet. 2015;115:249-63.

55. Phillips CM, Goumidi L, Bertrais S, Field MR, Peloso GM, Shen J, et al. Dietary saturated fat modulates the association between STAT3 polymorphisms and abdominal obesity in adults. J Nutr. 2009;139:2011-7.

56. Massiera F, Saint-Marc P, Seydoux J, Murata T, Kobayashi T, Narumiya S, et al Arachidonic acid and prostacyclin signaling promote adipose tissue development: a human health concern? J Lipid Res. 2003:44:271-9.

\section{Publisher's Note}

Springer Nature remains neutral with regard to jurisdictional claims in published maps and institutional affiliations.
Ready to submit your research? Choose BMC and benefit from:

- fast, convenient online submission

- thorough peer review by experienced researchers in your field

- rapid publication on acceptance

- support for research data, including large and complex data types

- gold Open Access which fosters wider collaboration and increased citations

- maximum visibility for your research: over $100 \mathrm{M}$ website views per year

At $\mathrm{BMC}$, research is always in progress.

Learn more biomedcentral.com/submissions 